\title{
Neutrophil Subsets in Periodontal Health and Disease: A Mini Review
}

\author{
Josefine Hirschfeld* \\ Department of Periodontology, Birmingham Dental School and Hospital, Birmingham, United Kingdom
}

Neutrophils are amongst the most abundant immune cells within the periodontal tissues and oral cavity. As innate immune cells, they are first line defenders at the tooth-mucosa interface, and can perform an array of different functions. With regard to these, it has been observed over many years that neutrophils are highly heterogeneous in their behavior. Therefore, it has been speculated that neutrophils, similarly to other leukocytes, exist in distinct subsets. Several studies have investigated different markers of neutrophils in oral health and disease in recent years in order to define potential cell subsets and their specific tasks. This research was inspired by recent advancements in other fields of medicine in this field. The aim of this review is to give an overview of the current evidence regarding the existence and presence of neutrophil subsets and their possible functions, specifically in the context of periodontitis, gingivitis, and periodontal health.

Keywords: phenotypal marker, cell function and behavior, subset, neutrophils, cluster of differentiation, periodontitis

\section{OPEN ACCESS}

Edited by:

Avi-Hai Hovav,

Hebrew University of Jerusalem, Israel

Reviewed by:

Octavio Alberto Gonzalez, University of Kentucky, United States Michael Glogauer,

University of Toronto, Canada

${ }^{*}$ Correspondence:

Josefine Hirschfeld j.hirschfeld@bham.ac.uk

Specialty section:

This article was submitted to Mucosal Immunity,

a section of the journal

Frontiers in Immunology

Received: 04 September 2018 Accepted: 06 December 2019 Published: 08 January 2020

Citation:

Hirschfeld J (2020) Neutrophil Subsets in Periodontal Health and Disease: A Mini Review. Front. Immunol. 10:3001. doi: 10.3389/fimmu.2019.03001

\section{INTRODUCTION}

Neutrophils are found in high abundance within the periodontal tissues and oral cavity. They typically migrate from local capillaries within the periodontal tissues toward the gingival crevice, following the highest concentration of a chemotactic gradient (1). The permanent presence of microbial and biofilm-derived chemotactic and pro-inflammatory factors attract neutrophils from the circulation into the tissues, where they become activated. Once in the gingival crevice, neutrophils are washed into the oral cavity. Even under healthy conditions, neutrophils constantly infiltrate the periodontium, although in lower numbers than during inflammation. Activated neutrophils have the aim to eliminate or reduce the microbial/antigenic load. The mechanisms by which they contribute to homeostasis and defense are (a) phagocytosis, the ingestion, and intracellular decomposition of antigens, (b) degranulation, the intra- or extracellular release of granule contents such as enzymes and antimicrobial peptides, (c) intra- or extracellular release of reactive oxygen species (ROS), which are directly cytotoxic to microbes but also to host cells, and (d) the formation of neutrophil extracellular traps (NETs), by which neutrophils release decondensed chromatin decorated with histones and granule contents into the extracellular space where they trap microorganisms. All of these processes are closely related, as effective internal degradation of microbes requires intracellular ROS release and degranulation, and as NET formation is usually preceded by ROS formation and accompanied by degranulation (2-5).

Neutrophils are well-researched cells of the innate immune system and yet, new discoveries have been constantly made. Neutrophils are widely believed to be the key cell that mediates tissue destruction and have been described as double-edged swords of immunity. In the periodontium, whilst absence of proper neutrophil function, as seen in some hereditary diseases, like PapillonLefèvre syndrome, leads to deleterious periodontal inflammation with severe tissue damage and tooth loss (6), neutrophil hyperactivity is equally associated with tissue damage (7). It has been long 
noted that neutrophils are heterogeneous in their behavior and perform vastly different functions. For example, only a proportion of neutrophils forms NETs, where the size of that proportion depends upon the stimulus and its concentration $(8,9)$. Therefore, the question has been raised whether distinct neutrophil subsets may exist and more attention has been given to the research of this possibility.

Potential pro- and anti-inflammatory roles of neutrophil subsets have been demonstrated in recent models of ischaemiarelated injury, trauma, cancer, sepsis, and inflammatory diseases $(10,11)$. Within the oral cavity, different neutrophil subsets and pro-inflammatory neutrophil phenotypes in periodontitis have also been proposed. This mini review aims at summarizing and discussing the current evidence regarding the presence of potential neutrophil subsets and phenotypes in the context of oral health and disease. Those studies are highlighted which have carried out biomarker analysis along with functional assays (Table 1).

\section{IDENTIFICATION OF NEUTROPHILS AND NEUTROPHIL SUBSETS}

Traditionally, neutrophils can be readily identified by their typical nuclear shape, in combination with histological hematoxylin and eosin staining (23). Furthermore, on human neutrophils isolated from different sites and in different states of health and activation, 141 cluster of differentiation (CD) markers have been described (24). Mostly, CD11b (integrin subunit alpha $\mathrm{M}$ adhesion molecule), CD14 (pattern recognition co-receptor), CD15 (a molecule expressed in the granulocytic series past the myeloblast stage), CD16 (Fc gamma receptor $(\mathrm{F} c \gamma \mathrm{R})$ IIIb, low-affinity immunoglobulin (Ig) G receptor), and CD62L (L-selectin, a cell adhesion molecule) $(25,26)$ have been used individually or in combination to identify pure human neutrophil populations (24). Moreover, several receptors on the neutrophil surface initiate the phagocytic signaling pathway. Phagocytosis is significantly enhanced by the presence of opsonins such as antibodies or complement factors on the microbial surface. Receptors specific for the Fc-region of antibodies include CD64 (Fc $\gamma \mathrm{RI}), \mathrm{CD} 32$ (Fc $\gamma$ RIIa), CD16, and CD89 (FcaR, IgA receptor) (27). Furthermore, neutrophils recognize complement-opsonized microorganisms using the complement receptors (CRs) CD35 (CR1), CD11b/CD18 (CR3), and CD11c/CD18 (CR4) (27).

Leliefeld et al. showed that during acute inflammation, a subset of $\mathrm{CD} 16^{\text {bright }} / \mathrm{CD} 62 \mathrm{~L}^{\mathrm{dim}}$ hyper-segmented human neutrophils displayed normal phagocytosis, associated with a remarkably poor capacity to contain bacteria intracellularly (28). Conversely, CD16 ${ }^{\text {dim }}$-banded neutrophils were the only neutrophil subset that adequately contained bacteria. The authors concluded that these results were indicative of a clear neutrophil heterogeneity in their antimicrobial capacity. Several markers of neutrophil degranulation have also been reported. The surface markers are CD63 (primary/azurophilic granules), CD15 and CD66b (secondary/specific granules) as well as CD11b (tertiary/gelatinase granules) and CD13, CD14,
CD18, CD45 (quaternary/secretory granules) (29). Another glycoprotein detected within specific granules is Olfactomedin4 (OLFM4). OLFM4 mRNA has been detected in progenitor neutrophils. However, the protein is only detected in $20-25 \%$ of peripheral blood neutrophils (30), suggesting that its expression is regulated by translation mechanisms that lead to functional heterogeneity (31).

The markers described above are not exclusive to neutrophils and have been reported on other cells also, such as macrophages, B- and T-lymphocytes (32). A marker specific to neutrophils is CD177, a glycoprotein expressed on the neutrophil plasma membrane as well as on the membrane of their specific granules (33). However, the proportion of $\mathrm{CD}_{177^{+}}$neutrophils varies amongst individuals, some displaying bimodal (high and no CD177) or trimodal (high, intermediate, and no CD177) expression. Approximately $1-10 \%$ of humans show a complete absence of $\mathrm{CD}_{177^{+}}$cells. This has been attributed to the allelic frequency of a mutation in the CD177 gene (31). Due to its heterogeneity, this marker may not be reliable for quantification purposes, but it delineates PMN populations reliably in those individuals who express it. Neutrophil granules have also been used to describe distinct phenotypes: during acute and chronic inflammation a population of neutrophils, which co-sediments with peripheral blood mononuclear cells (PBMCs), has been reported. Typically, circulating neutrophils are separated from PBMCs by gradient centrifugation, as neutrophils have a higher density than PBMCs. Therefore, this neutrophil population has been termed low-density neutrophils (LDNs) (34).

Neutrophils are classically implicated in inflammation, but have some pro-resolving properties also. Firstly, their role as apoptotic cells in the macrophage-mediated resolution of inflammation is believed to be crucial (35). In this process, apoptotic neutrophils induce a suppression of nuclear factor kappa B signaling in macrophages, and therefore a reduction in the release of pro- but not anti-inflammatory cytokines from these cells (36). Secondly, neutrophils are co-producers of the pro-resolving lipid mediators lipoxins and maresin-1 $(37,38)$.

Thirdly, an immunosuppressive and pro-tumorigenic neutrophil type (N2) has been described previously (39). It features a reduction in Fas-ligand expression, down-regulation of the pathways associated with antigen processing, and a dependency on tissue growth factor beta (TGF- $\beta$ ) signaling (40, 41). Earlier, a similar neutrophil subset with $\mathrm{T}$ cellsuppressive properties had been described by Pillay et al. which was mainly based on CD16 and CD62L expression patterns along with nuclear morphology and suppression of $\mathrm{T}$ cell proliferation after stimulation with lipopolysaccharide (42). Interestingly, these populations also displayed differences in their survival time and ROS release. Lastly, neutrophils contribute to tissue repair and remodeling, as they produce not only matrix metalloproteinases (MMPs) removing tissue debris at the site of injury, but also tissue inhibitors of MMPs (TIMPs), preventing tissue damage by MMPs, as well as growth factors and pro-angiogenic factors (43). Indeed, a pro-angiogenic neutrophil subset has been observed in human healing wounds. It is characterized by the markers CXCR4, vascular endothelial growth factor receptor 1 (VEGFR1), and integrin alpha subunit 


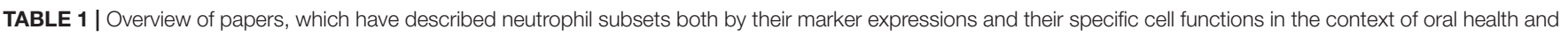
inflammation.

\begin{tabular}{|c|c|c|c|}
\hline References & $\begin{array}{l}\text { Neutrophil test populations, oral health } \\
\text { status, and control samples }\end{array}$ & $\begin{array}{l}\text { Neutrophil markers described in the } \\
\text { test population }\end{array}$ & Functional properties of population \\
\hline Wilton et al. (12) & $\begin{array}{l}\text { Gingival crevicular fluid neutrophils from } \\
\text { healthy donors vs. blood neutrophils }\end{array}$ & Defective or low CD35 & Impaired phagocytosis \\
\hline Van Dyke et al. (13) & $\begin{array}{l}\text { Blood neutrophils from patients with } \\
\text { aggressive periodontitis vs. periodontally } \\
\text { healthy donors }\end{array}$ & CD11blow & Impaired chemotaxis \\
\hline Nemoto et al. (14) & $\begin{array}{l}\text { Blood neutrophils from patients with } \\
\text { aggressive periodontitis vs. periodontally } \\
\text { healthy donors }\end{array}$ & CD16 ${ }^{\text {low }}$, CD11a high, CD11b high & Impaired chemotaxis \\
\hline Miyazaki et al. (15) & $\begin{array}{l}\text { Blood neutrophils from patients with chronic } \\
\text { periodontitis vs. blood neutrophils }\end{array}$ & CD16 low, $\mathrm{CD}^{\text {low }}$ & Impaired phagocytosis \\
\hline Kobayashi et al. (16) & $\begin{array}{l}\text { Blood neutrophils from patients with chronic } \\
\text { periodontitis vs. periodontally healthy donors }\end{array}$ & CD16b allotype NA2low & $\begin{array}{l}\text { Impaired phagocytosis and ROS release in } \\
\text { response to IgG-opsonized bacteria }\end{array}$ \\
\hline Kobayashi et al. (17) & $\begin{array}{l}\text { Gingival crevicular fluid neutrophils from } \\
\text { patients with chronic periodontitis vs. blood } \\
\text { neutrophils }\end{array}$ & CD89high, CD64 $^{\text {high }}$, CD16b ${ }^{\text {low }}$, CD32alow & $\begin{array}{l}\text { Impaired phago-cytosis of IgG-opsonized } \\
\text { bacteria }\end{array}$ \\
\hline Fine et al. (18) & $\begin{array}{l}\text { Oral neutrophils from patients with chronic } \\
\text { periodontitis vs. Para1 and Para2 neutrophils }\end{array}$ & $\begin{array}{l}\text { CD10 }{ }^{\text {high }}, \mathrm{CD}^{\text {high }}, \mathrm{CD} 64^{\text {high }}, \mathrm{CD} 66 \mathrm{a}^{\text {high }} \\
\text { CD11 } \mathrm{b}^{\text {high }}, \mathrm{CD} 18^{\text {high }}, \mathrm{CD} 55^{\text {high }}\end{array}$ & $\begin{array}{l}\text { Increased phagocytosis, NET formation, ROS } \\
\text { release, and degranulation }\end{array}$ \\
\hline Fine et al. (18) & $\begin{array}{l}\text { Oral neutrophils (Para2) from healthy donors } \\
\text { vs. Para1 neutrophils }\end{array}$ & $\begin{array}{l}\text { CD55 high }, \text { CD63 }^{\text {high }}, \text { CD170 low }, \text { CD16 } \\
\text { FSC-A } \\
\text { low }, \text { SSC-A }\end{array}$ & $\begin{array}{l}\text { Increased phagocytosis, NET formation, and } \\
\text { unstimulated ROS release }\end{array}$ \\
\hline Rijkschroeff et al. (19) & $\begin{array}{l}\text { Oral neutrophils from healthy donors vs. } \\
\text { blood neutrophils }\end{array}$ & CD16 ${ }^{\text {high }}, \mathrm{CD} 11 \mathrm{~b}^{\text {high }}, \mathrm{CD} 3^{\text {high }}, \mathrm{CD} 66 \mathrm{~b}^{\text {high }}$ & Increased unstimulated ROS release \\
\hline Rijkschroeff et al. (20) & $\begin{array}{l}\text { Oral neutrophils from edentulous donors vs. } \\
\text { dentate donors with no or mild forms of } \\
\text { periodontitis }\end{array}$ & CD16 ${ }^{\text {high }} \mathrm{CD} 11 \mathrm{~b}^{\text {low }}, \mathrm{CD}^{\mathrm{low}}, \mathrm{CD} 66 \mathrm{~b}^{\text {low }}$ & Decreased unstimulated ROS release \\
\hline Moonen et al. (21) & $\begin{array}{l}\text { Oral neutrophils from healthy donors vs. } \\
\text { blood neutrophils }\end{array}$ & fMLPR ${ }^{\text {low }}$ & $\begin{array}{l}\text { Impaired chemotaxis, increased } \\
\text { phagocytosis, and unstimulated NET release }\end{array}$ \\
\hline
\end{tabular}

Periodontitis in these studies was diagnosed according to the 1999 classification system (22).

CD49d. This subset represented $\sim 3 \%$ of total circulating neutrophils (44). These neutrophils produced significantly higher amounts of MMP-9 than pro-inflammatory neutrophils, which was thought to contribute extracellular matrix remodeling at these healing sites, rather than to the extracellular matrix damage mediated by activated inflammatory neutrophils (45).

\section{POSSIBLE NEUTROPHIL SUBSETS IN PERIODONTAL HEALTH AND INFLAMMATION}

Neutrophils have been identified by means of surface marker detection in high numbers in periodontal tissues (46), gingival crevicular fluid (GCF) (47) and in the oral cavity $(24,27)$. The presence of oral neutrophils in edentulous subjects has also been demonstrated, suggesting that neutrophils can transmigrate the oral mucosa directly (20). Neutrophils have also been identified within supragingival dental biofilms by means of their CD177 marker (48), indicating that oral PMNs are incorporated into oral biofilms. The functions of those neutrophil surface markers described in the context of periodontal diseases and lined out in Table 1 are explained in Table 2.

Since the 1970s, neutrophil markers in relation to cell function have been investigated in the context of oral health and disease. In 1977, Wilton et al. discovered that only half of the GCF-derived neutrophils isolated from healthy donors expressed the complement receptor C3bR (CD35) and that this led to impaired phagocytosis compared to blood neutrophils (12). However, this assay was based on the assumption that zymosan particles had adsorbed complement factor C3b from serum rather than on identification of CD35. They also reported that the "Fc receptor system" was unimpeded. Later on, in 2000, Kobayashi et al. reported impaired phagocytosis and ROS release in response to IgG-opsonized Porphyromonas gingivalis and that these peripheral blood neutrophils from patients with periodontitis displayed a specific Fc $\gamma$ RIIIb allotype (NA2) (16). They further reported that GCF-derived neutrophils from these patients had increased Fc $\alpha$ RI and Fc $\gamma$ RI levels and lower Fc $\gamma$ RIIa and Fc $\gamma$ RIIIb levels than blood neutrophils, leading to the same impairment of phagocytosis $(15,17)$.

A neutrophil subset with defective chemotaxis in aggressive periodontitis (Grade 3 periodontitis, according to the 2017 classification scheme (49) was described by Van Dyke et al. $(13,50)$. The marker, which was diminished on blood-derived neutrophils in these studies, was CD11b (formerly glycoprotein 110), a molecule associated with neutrophil adhesion. Interestingly, the same group reported a diminished capacity of the labeled chemotactic factor N-formylmethionyl-leucylphenylalanine (fMLP) to bind to neutrophils in individuals 
TABLE 2 | Overview of the physiological functions of the neutrophil surface proteins and markers described in Table 1.

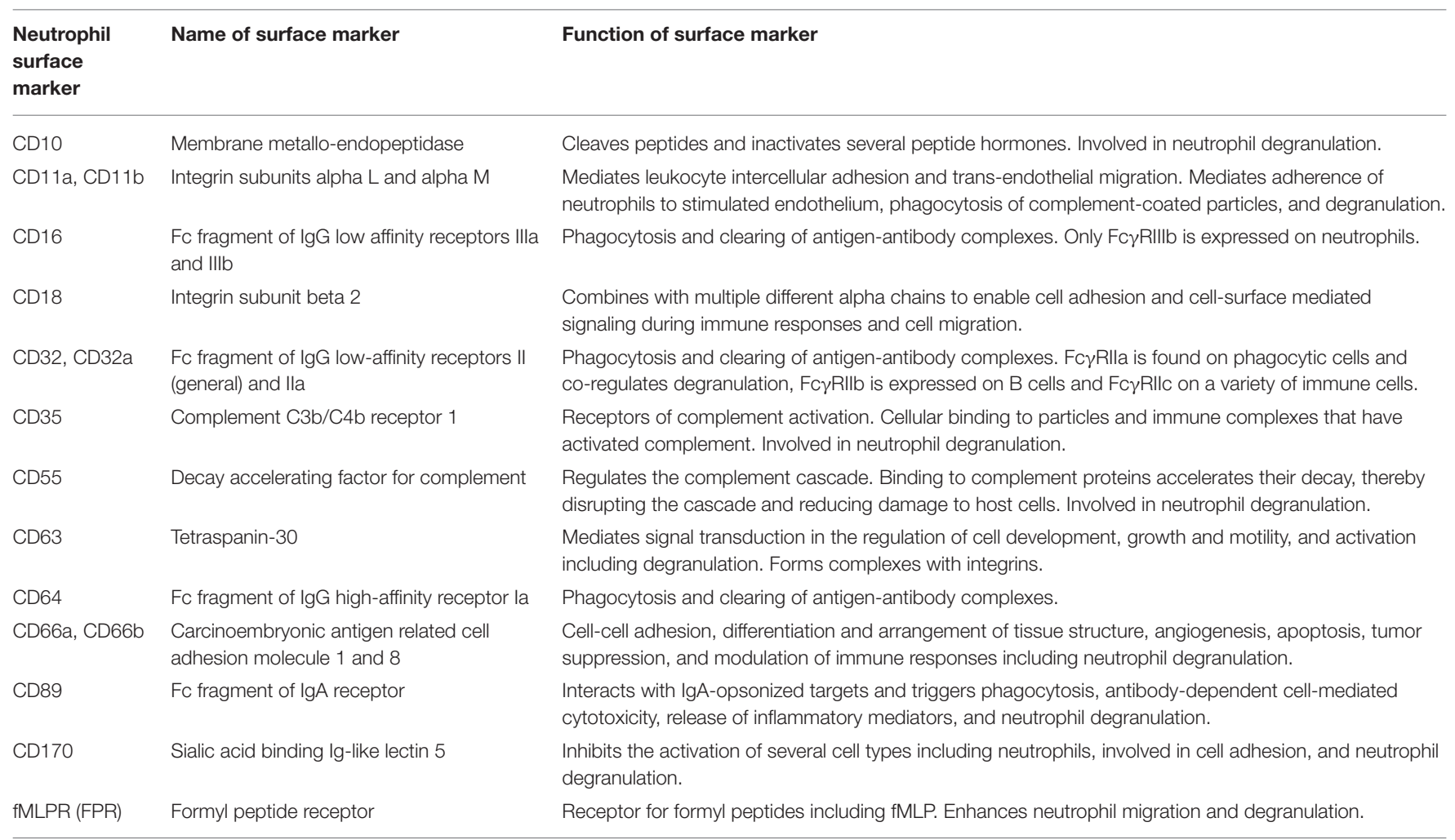

Source: NCBI (25).

with periodontitis, although the receptors themselves appeared to be functional $(51,52)$. In line with this finding, a 1997 study by Nemoto et al. demonstrated that blood-derived neutrophils from a similar patient cohort had low CD16, but higher CD11b and CD11b expression levels, and also showed impaired chemotactic capabilities (14). An inability of blood neutrophils from periodontitis patients to migrate in a directional manner and an unresponsiveness to fMLP has also been described elsewhere (53). Furthermore, a hyperactive and hyper-reactive neutrophil phenotype has been reported previously by different groups $(7,54,55)$, particularly with regard to ROS release. Although this phenotype has been attributed to higher levels of circulating bacterial products and pro-inflammatory cytokines originating from the periodontium, there is a possibility that these neutrophils may belong to a distinct subset as indicated by later studies, which are described below.

Technological developments over the past decades, particularly with regard to immunofluorescence and flow cytometry methods, have facilitated research of neutrophil markers and subsets, and have led to new insights in recent years. Much attention has been given to oral neutrophils isolated by means of mouth rinsing protocols. A large body of this work has been accomplished by Glogauer and co-workers, who compared neutrophil surface markers in oral and blood neutrophils, as well as in different health and disease states. In 2012, this group identified an oral neutrophil subset in healthy patients that expresses CD3, usually known as a T-cell receptor (56). Although specific interactions between neutrophils and $\mathrm{T}$ cells were not investigated in this paper, the finding corroborates the notion that neutrophils act as a bridge between the innate and adaptive immune systems. In 2016, they identified CD11b, CD16, and CD66b as markers that are consistently expressed on neutrophils independent of the cell location, level of activation and periodontal disease state (24), using high-throughput flow cytometry against a panel of 374 known CD antibodies. Furthermore, they newly identified neutrophil surface markers, which had not previously been described. These were CDw198 (C-C chemokine receptor 8), CDw199 (C-C chemokine receptor 9), CD322 (junctional adhesion molecule $\mathrm{B}$, usually known to be localized at tight junctions of endothelial and epithelial cells and to be involved in adhesion and leukocyte transendothelial migration [(25) as well as CD328 sialic acid-binding Ig-like lectin 7, an adhesion molecule (25)].

In the same year, this group reported a $\mathrm{CD}$ marker signature indicative of cell activation, which was expressed at much higher levels on oral neutrophils in periodontitis than on healthy oral neutrophils, therefore allowing the distinction between para- and pro-inflammatory neutrophil subsets (18). The para-inflammatory phenotype was defined as neutrophils in an intermediary state that allows them to interact with the oral microflora without eliciting a marked inflammatory response, thus contributing to homeostasis. 
The markers that were up-regulated on oral neutrophils of periodontitis patients were placed into three categories: markers of activation and degranulation (CD10, CD63, CD64, and CD66a), adhesion receptors (CD11b and CD18) and complement inhibitors (CD55).

The pro-inflammatory phenotype of periodontitis oral neutrophils was confirmed by elevated degranulation, phagocytosis, ROS production, and NET formation. In oral health, the authors observed two different populations of oral neutrophils. These differed in their size and granularity profile, in their expression of specific CD markers, production of ROS, and NET formation. The oral neutrophil phenotype present only in health had a forward scatter and side scatter profile similar to naïve blood neutrophils, and these cells were in a lower state of activation. At the same time, the other, more activated population showed higher expression of CD55 and CD63, whilst having decreased levels of inhibitory receptor CD170 and CD16. The authors concluded that a drop in CD16 in this population is likely a consequence of phagocytosis, and therefore is consistent with elevated phagocytic activity of this activated cell population.

Recently, in 2018, the same group reported that the surface expression of CD63, CD11b, CD16, and CD14 indicates an activation state in oral neutrophils (57), as the presence of these markers implies degranulation, adhesion and antigen recognition processes. They found that oral neutrophil activation was reduced in experimental gingivitis despite higher cell numbers, compared to those seen in health and during the resolution phase. Circulatory neutrophils, on the other hand, were shown to be activated during gingivitis onset as shown by the markers CD55, CD63, CD11b, and CD66a. Also in 2018, this group further characterized the morphology of the para-inflammatory health-associated phenotype described in 2016, and compared it to the naïve morphology of blood neutrophils as well as to the pro-inflammatory phenotype of oral neutrophils in periodontitis (58). They revealed that pro-inflammatory neutrophils in periodontitis showed less granulation, lighter cytoplasms and higher amounts of nuclear euchromatin, as assessed by electron microscopy, compared to the para-inflammatory oral health neutrophils. The periodontitis oral neutrophils also contained more phagosomes with and without undigested bacteria. Neutrophils in gingival tissues displayed naïve morphology when viewed in the blood vessels and gradually showed pro-inflammatory morphological changes as they traveled toward the epithelium.

Another group of researchers led by Nicu and Loos, have also been investigating oral neutrophils by their surface markers (19). They described that in oral neutrophils from healthy donors without additional stimulation, these cells were more activated than circulatory neutrophils, as indicated by higher expression of CD11b, CD63, and CD66b, and elevated constitutive ROS release. The authors concluded that oral neutrophils are in a more mature stage of their life cycle compared with peripheral blood neutrophils, but that they are still responsive to stimulation. Two years later, they published data regarding oral neutrophils from periodontitis patients, and reported that CD11b was elevated in these neutrophils compared to those from healthy controls (59), confirming results from the Glogauer group.
Interestingly, this group also investigated oral neutrophils in edentulous patients and found that they expressed low levels of all three activation markers and low constitutive ROS release (20). In a recent publication, these researchers characterized oral neutrophils as terminally migrated cells and reported that oral neutrophils had lost their ability to migrate in a coordinated directional manner (21). They showed that the fMLP receptor, crucial for fMLP-mediated chemotaxis, was detectable in only half of the neutrophils, compared to blood neutrophils. They reasoned that the AMLP receptor was saturated with fMLP from the oral environment and that therefore neutrophils were desensitized to fMLP. In future studies, it would be interesting to investigate whether these receptors are indeed saturated or expressed to a lesser level, as this would give further hints toward a possible novel phenotype of oral neutrophils.

\section{CONCLUSION}

There is a multitude of reports confirming that blood, tissue, and oral neutrophils act in heterogeneous manners, and that different neutrophil populations and phenotypes exist. It is currently not clear, however, whether neutrophils of the periodontium and oral cavity express or lack certain surface markers in response to stimuli and activation, or whether true subsets exist that shape the specific response of these cells. For example, during the process of transmigration, neutrophils substantially alter their surface marker expression pattern toward higher expression of integrins, chemokines and proteases, and also show delayed apoptosis (10). In this context, the changes in these measurable markers is likely due to their momentary activity rather than reflecting a specific cell subset. At the same time, certain markers such as CD177 appear to be more influenced by the genetic background than by stimuli and cell function. It is also important to consider that oral neutrophils are terminally migrated cells, are under high osmotic stress conditions in saliva compared to blood (60) and are exposed to a high load of microbes, antigens and toxins. These conditions are likely to influence measurable neutrophil parameters, such as granularity, size, release of substances, and possibly the expression of surface markers.

On the other hand, in several systemic diseases, more evidence has been gathered with regard to the existence of true subsets. Studies in the context of oral health and inflammation need to be undertaken bringing together observations of distinct neutrophil populations, markers and behaviors. For example, future studies may be aimed at co-localizing specific CD markers and indicators of neutrophil activity, such as hyper-citrullinated histone for NET formation, or at investigating the influence of different stimuli that activate neutrophils upon the CD marker profile. In many previous studies, flow cytometry has been employed as the main method of neutrophil marker detection, which is a highly suitable tool for this type of research. However, few studies have reported these data in accordance with the MIFlowCyt guidelines proposed by Lee et al. (61). A lack of information regarding gating strategies, instrument settings, and color compensation 
methods, makes it difficult to critically appraise these data and to reproduce experiments. Therefore, in future studies, these guidelines for reporting flow cytometry data should be adhered to by researchers, which can also help to make data from different research groups more comparable. This seminal field of research has the potential to identify neutrophil populations in the future, which could be utilized as targets in translational research and raise new therapeutic possibilities.

\section{REFERENCES}

1. Barros SP, Williams R, Offenbacher S, Morelli T. Gingival crevicular fluid as a source of biomarkers for periodontitis. Periodontology. (2016) 70:53-64. doi: $10.1111 /$ prd.12107

2. Brinkmann V, Reichard U, Goosmann C, Fauler B, Uhlemann Y, Weiss DS, et al. Neutrophil extracellular traps kill bacteria. Science. (2004) 303:1532-5. doi: 10.1126/science. 1092385

3. Segal AW. How neutrophils kill microbes. Ann Rev Immunol. (2005) 23:197223. doi: 10.1146/annurev.immunol.23.021704.115653

4. Nishinaka Y, Arai T, Adachi S, Takaori-Kondo A, Yamashita K. Singlet oxygen is essential for neutrophil extracellular trap formation. Biochem Biophys Res Commun. (2011) 413:75-9. doi: 10.1016/j.bbrc.2011.08.052

5. Palmer LJ, Cooper PR, Ling MR, Wright HJ, Huissoon A, Chapple IL. Hypochlorous acid regulates neutrophil extracellular trap release in humans. Clin Exp Immunol. (2012) 167:261-8. doi: 10.1111/j.1365-2249.2011.04518.x

6. Roberts H, White P, Dias I, Mckaig S, Veeramachaneni R, Thakker N, et al. Characterization of neutrophil function in Papillon-Lefevre syndrome. J Leukoc Biol. (2016) 100:433-44. doi: 10.1189/jlb.5A1015-489R

7. Matthews JB, Wright HJ, Roberts A, Cooper PR, Chapple ILC. Hyperactivity and reactivity of peripheral blood neutrophils in chronic periodontitis. Clin ExpImmunol. (2007) 147:255-64. doi: 10.1111/j.1365-2249.2006.03276.x

8. Kenny EF, Herzig A, Krüger R, Muth A, Mondal S, Thompson PR, et al. Diverse stimuli engage different neutrophil extracellular trap pathways. eLife. (2017) 6:e24437. doi: 10.7554/eLife.24437.032

9. De Bont CM, Koopman WJH, Boelens WC, Pruijn GJM. Stimulus-dependent chromatin dynamics, citrullination, calcium signalling and ROS production during NET formation. Biochim Biophys Acta Mol Cell Res. (2018) 1865:16219. doi: 10.1016/j.bbamcr.2018.08.014

10. Beyrau M, Bodkin JV, Nourshargh S. Neutrophil heterogeneity in health and disease: a revitalized avenue in inflammation and immunity. Open Biol. (2012) 2:120134. doi: 10.1098/rsob.120134

11. Garley M, Jabłonska E. Heterogeneity among neutrophils. Arch Immunol Ther Ex. (2018) 66:21-30. doi: 10.1007/s00005-0170476-4

12. Wilton JM, Renggli $\mathrm{HH}$, Lehner T. The role of $\mathrm{Fc}$ and $\mathrm{C} 3 \mathrm{~b}$ receptors in phagocytosis by inflammatory polymorphonuclear leucocytes in man. Immunology. (1977) 32:955-61.

13. Van Dyke TE, Wilson-Burrows C, Offenbacher S, Henson P. Association of an abnormality of neutrophil chemotaxis in human periodontal disease with a cell surface protein. Infect Immun. (1987) 55:2262-7.

14. Nemoto E, Nakamura M, Shoji S, Horiuchi H. Circulating promyelocytes and low levels of CD16 expression on polymorphonuclear leukocytes accompany early-onset periodontitis. Infect Immun. (1997) 65:3906-12.

15. Miyazaki A, Kobayashi T, Suzuki T, Yoshie H, Hara K. Loss of Fc gamma receptor and impaired phagocytosis of polymorphonuclear leukocytes in gingival crevicular fluid. J Periodontal Res. (1997) 32:439-46. doi: 10.1111/j.1600-0765.1997.tb00556.x

16. Kobayashi T, Van Der Pol WL, Van De Winkel JG, Hara K, Sugita $\mathrm{N}$, Westerdaal NA, et al. Relevance of IgG receptor IIIb (CD16) polymorphism to handling of Porphyromonas gingivalis: implications for the pathogenesis of adult periodontitis. J Periodontal Res. (2000) 35:65-73. doi: 10.1034/j.1600-0765.2000.035002065.x

17. Kobayashi T, Yamamoto K, Sugita N, Van Spriel AB, Kaneko S, Van De Winkel JG, et al. Effective in vitro clearance of Porphyromonas gingivalis by Fc alpha

\section{AUTHOR CONTRIBUTIONS}

$\mathrm{JH}$ conceptualized and wrote the article, and prepared the tables.

\section{FUNDING}

This work was supported by the Academy of Medical Sciences (SGL019/1024).

receptor I (CD89) on gingival crevicular neutrophils. Infect Immun. (2001) 69:2935-42. doi: 10.1128/IAI.69.5.2935-2942.2001

18. Fine N, Hassanpour S, Borenstein A, Sima C, Oveisi M, Scholey J, et al. Distinct oral neutrophil subsets define health and periodontal disease states. $J$ Dent Res. (2016) 95:931-8. doi: 10.1177/0022034516645564

19. Rijkschroeff P, Jansen IDC, Van Der Weijden FA, Keijser BJF, Loos BG, Nicu EA. Oral polymorphonuclear neutrophil characteristics in relation to oral health: a cross-sectional, observational clinical study. Int J Oral Sci. (2016) 8:191-8. doi: 10.1038/ijos.2016.23

20. Rijkschroeff P, Loos BG, Nicu EA. Impaired polymorphonuclear neutrophils in the oral cavity of edentulous individuals. Eur J Oral Sci. (2017) 125:371-8. doi: $10.1111 /$ eos. 12367

21. Moonen CG, Hirschfeld J, Cheng L, Chapple IL, Loos BG, Nicu EA. Oral neutrophils characterized: chemotactic, phagocytic, and neutrophil extracellular trap (NET) formation properties. Front Immunol. (2019) 10:635. doi: 10.3389/fimmu.2019.00635

22. Armitage GC. Development of a classification system for periodontal diseases and conditions. Ann. Periodontol. (1999) 4:1-6. doi: 10.1902/annals.1999.4.1.1

23. Peckham M, Knibbs A, Paxton S. Histology Guide. Universtiy of Leeds, UK: Faculty of Biological Sciences (2003). Available online at: https://www. histology.leeds.ac.uk/blood/blood_wbc.php (accessed December 06, 2019).

24. Lakschevitz FS, Hassanpour S, Rubin A, Fine N, Sun C, Glogauer M. Identification of neutrophil surface marker changes in health and inflammation using high-throughput screening flow cytometry. Exp Cell Res. (2016) 342:200-9. doi: 10.1016/j.yexcr.2016.03.007

25. NCBI (1988). Gene. Bethesda, MD: National Library of Medicine (US): National Center for Biotechnology Information. Available online at: https:// www.ncbi.nlm.nih.gov/gene/ (accessed December 06, 2019).

26. Nakayama F, Nishihara S, Iwasaki H, Kudo T, Okubo R, Kaneko $\mathrm{M}$, et al. CD15 expression in mature granulocytes is determined by alpha 1,3-fucosyltransferase IX, but in promyelocytes and monocytes by alpha 1,3-fucosyltransferase IV. J Biol Chem. (2001) 276:16100-6. doi: 10.1074/jbc.M007272200

27. Rijkschroeff P, Loos BG, Nicu EA. Oral polymorphonuclear neutrophil contributes to oral health. Curr Oral Health Rep. (2018) 5:211-20. doi: 10.1007/s40496-018-0199-6

28. Leliefeld PHC, Pillay J, Vrisekoop N, Heeres M, Tak T, Kox M, et al. Differential antibacterial control by neutrophil subsets. Blood Adv. (2018) 2:1344-55. doi: 10.1182/bloodadvances.2017015578

29. Naegelen I, Beaume N, Plançon S, Schenten V, Tschirhart EJ, Bréchard S. Regulation of neutrophil degranulation and cytokine secretion: a novel model approach based on linear fitting. J Immunol Res. (2015) 2015:817038. doi: 10.1155/2015/817038

30. Clemmensen SN, Bohr CT, Rørvig S, Glenthøj A, Mora-Jensen H, Cramer EP, et al. Olfactomedin 4 defines a subset of human neutrophils. J Leukoc Biol. (2012) 91:495-500. doi: 10.1189/jlb.0811417

31. Deniset JF, Kubes P. Neutrophil heterogeneity: Bona fide subsets or polarization states? J Leukoc Biol. (2018) 103:829-38. doi: 10.1002/JLB.3RI0917-361R

32. Minnema-Luiting J, Vroman H, Aerts J, Cornelissen R. Heterogeneity in immune cell content in malignant pleural mesothelioma. Int J Mol Sci. (2018) 19:1041. doi: 10.3390/ijms19041041

33. Goldschmeding R, Van Dalen CM, Faber N, Calafat J, Huizinga TW, Van Der Schoot CE, et al. Further characterization of the NB 1 antigen as a variably expressed 56-62 kD GPI-linked glycoprotein of plasma membranes 
and specific granules of neutrophils. Br J Haematol. (1992) 81:336-45. doi: 10.1111/j.1365-2141.1992.tb08237.x

34. Carmona-Rivera C, Kaplan MJ. Low-density granulocytes: a distinct class of neutrophils in systemic autoimmunity. Semin Immunopathol. (2013) 35:45563. doi: $10.1007 / \mathrm{s} 00281-013-0375-7$

35. El Kebir D, Filep JG. Targeting neutrophil apoptosis for enhancing the resolution of inflammation. Cells. (2013) 2:330-48. doi: 10.3390/cells2020330

36. Marwick JA, Mills R, Kay O, Michail K, Stephen J, Rossi AG, et al. Neutrophils induce macrophage anti-inflammatory reprogramming by suppressing NF- $\mathrm{\kappa B}$ activation. Cell Death Dis. (2018) 9:665. doi: 10.1038/s41419-018-0710-y

37. Brezinski ME, Serhan CN. Selective incorporation of (15S)hydroxyeicosatetraenoic acid in phosphatidylinositol of human neutrophils: agonist-induced deacylation and transformation of stored hydroxyeicosanoids. PNAS. (1990) 87:6248-52. doi: 10.1073/pnas.87.16.6248

38. Abdulnour R-EE, Dalli J, Colby JK, Krishnamoorthy N, Timmons JY, Tan $\mathrm{SH}$, et al. Maresin 1 biosynthesis during platelet-neutrophil interactions is organ-protective. PNAS. (2014) 111:16526-31. doi: 10.1073/pnas.1407123111

39. Cuartero MI, Ballesteros I, Moraga A, Nombela F, Vivancos J, Hamilton JA, et al. N2 neutrophils, novel players in brain inflammation after stroke: modulation by the PPAR $\gamma$ agonist rosiglitazone. Stroke. (2013) 44:3498-508. doi: 10.1161/STROKEAHA.113.002470

40. Fridlender ZG, Sun J, Kim S, Kapoor V, Cheng G, Ling L, et al. Polarization of tumor-associated neutrophil phenotype by TGF-beta: "N1" versus "N2" TAN. Cancer Cell. (2009) 16:183-94. doi: 10.1016/j.ccr.2009.06.017

41. Prame Kumar K, Nicholls AJ, Wong CHY. Partners in crime: neutrophils and monocytes/macrophages in inflammation and disease. Cell Tissue Res. (2018) 371:551-65. doi: 10.1007/s00441-0172753-2

42. Pillay J, Kamp VM, Van Hoffen E, Visser T, Tak T, Lammers J-W, et al. A subset of neutrophils in human systemic inflammation inhibits $\mathrm{T}$ cell responses through Mac-1. J Clin Invest. (2012) 122:327-36. doi: 10.1172/JCI57990

43. Wang J. Neutrophils in tissue injury and repair. Cell Tissue Res. (2018) 371:531-9. doi: 10.1007/s00441-017-2785-7

44. Massena S, Christoffersson G, Vagesjo E, Seignez C, Gustafsson K, Binet F, et al. Identification and characterization of VEGF-A-responsive neutrophils expressing CD49d, VEGFR1, and CXCR4 in mice and humans. Blood. (2015) 126:2016-26. doi: 10.1182/blood-2015-03-631572

45. Christoffersson G, Vagesjo E, Vandooren J, Liden M, Massena S, Reinert $\mathrm{RB}$, et al. VEGF-A recruits a proangiogenic MMP-9-delivering neutrophil subset that induces angiogenesis in transplanted hypoxic tissue. Blood. (2012) 120:4653-62. doi: 10.1182/blood-2012-04-421040

46. Dutzan N, Konkel JE, Greenwell-Wild T, Moutsopoulos NM. Characterization of the human immune cell network at the gingival barrier. Mucosal Immunol. (2016) 9:1163-72. doi: 10.1038/mi.2015.136

47. Suzuki T, Sugita N, Yoshie H, Hara K. Presence of activated eosinophils, high $\mathrm{IgE}$ and $\mathrm{sCD} 23$ titers in gingival crevicular fluid of patients with adult periodontitis. J Periodontal Res. (1995) 30:159-66. doi: 10.1111/j.1600-0765.1995.tb01268.x

48. Hirschfeld J, Dommisch H, Skora P, Horvath G, Latz E, Hoerauf A, et al. Neutrophil extracellular trap formation in supragingival biofilms. Int J Med Microbiol. (2015) 305:453-63. doi: 10.1016/j.ijmm.2015. 04.002

49. Caton JG, Armitage G, Berglundh T, Chapple ILC, Jepsen SS. A new classification scheme for periodontal and peri-implant diseases and conditions
- Introduction and key changes from the 1999 classification. JClin Periodontol. (2018) 45(Suppl 20):S1-8. doi: 10.1111/jcpe.12935

50. Van Dyke TE, Warbington M, Gardner M, Offenbacher S. Neutrophil surface protein markers as indicators of defective chemotaxis in LJP. J Periodontol. (1990) 61:180-4. doi: 10.1902/jop.1990.61.3.180

51. Van Dyke TE, Levine MJ, Tabak LA, Genco RJ. Reduced chemotactic peptide binding in juvenile periodontitis: a model for neutrophil function. Biochem Biophys Res Commun. (1981) 100:1278-84. doi: 10.1016/0006-291X(81)91962-8

52. Van Dyke TE, Zinney W, Winkel K, Taufiq A, Offenbacher S, Arnold RR. Neutrophil function in localized juvenile periodontitis. Phagocytosis, superoxide production and specific granule release. J Periodontol. (1986) 57:703-8. doi: 10.1902/jop.1986.57.11.703

53. Roberts HM, Ling MR, Insall R, Kalna G, Spengler J, Grant MM, et al. Impaired neutrophil directional chemotactic accuracy in chronic periodontitis patients. J Clin Periodontol. (2015) 42:1-11. doi: $10.1111 /$ jcpe. 12326

54. Fredriksson MI, Gustafsson AK, Bergstrom KG, Asman BE. Constitutionally hyperreactive neutrophils in periodontitis. J Periodontol. (2003) 74:219-24. doi: 10.1902/jop.2003.74.2.219

55. Johnstone AM, Koh A, Goldberg MB, Glogauer M. A hyperactive neutrophil phenotype in patients with refractory periodontitis. J Periodontol. (2007) 78:1788-94. doi: 10.1902/jop.2007.070107

56. Lakschevitz FS, Aboodi GM, Glogauer M. Oral neutrophils display a site-specific phenotype characterized by expression of T-cell receptors. $J$ Periodontol. (2013) 84:1493-503. doi: 10.1902/jop.2012.120477

57. Wellappuli NC, Fine N, Lawrence HP, Goldberg M, Tenenbaum HC, Glogauer M. Oral and blood neutrophil activation states during experimental gingivitis. JDR Clin Trans Res. (2018) 3:65-75. doi: 10.1177/2380084417742120

58. Borenstein A, Fine N, Hassanpour S, Sun C, Oveisi M, Tenenbaum HC, et al. Morphological characterization of para- and proinflammatory neutrophil phenotypes using transmission electron microscopy. J Periodontal Res. (2018) 53:972-82. doi: $10.1111 /$ jre. 12595

59. Nicu EA, Rijkschroeff P, Wartewig E, Nazmi K, Loos BG. Characterization of oral polymorphonuclear neutrophils in periodontitis patients: a case-control study. BMC Oral Health. (2018) 18:149-149. doi: 10.1186/s12903-018-0615-2

60. Villiger M, Stoop R, Vetsch T, Hohenauer E, Pini M, Clarys P, et al. Evaluation and review of body fluids saliva, sweat and tear compared to biochemical hydration assessment markers within blood and urine. Eur J Clin Nutr. (2018) 72:69-76. doi: 10.1038/ejen.2017.136

61. Lee JA, Spidlen J, Boyce K, Cai J, Crosbie N, Dalphin M, et al. MIFlowCyt: the minimum information about a Flow Cytometry Experiment. Cytometry A. (2008) 73:926-30. doi: 10.1002/cyto.a.20623

Conflict of Interest: The author declares that the research was conducted in the absence of any commercial or financial relationships that could be construed as a potential conflict of interest.

Copyright (๑) 2020 Hirschfeld. This is an open-access article distributed under the terms of the Creative Commons Attribution License (CC BY). The use, distribution or reproduction in other forums is permitted, provided the original author $(s)$ and the copyright owner(s) are credited and that the original publication in this journal is cited, in accordance with accepted academic practice. No use, distribution or reproduction is permitted which does not comply with these terms. 